\title{
Study of Effect of Altered Piezometric Heads in Experimental Investigation of Bernoulli's Equation
}

\author{
Adil Wazeer ${ }^{1 *}$ and Kaushalendra Kumar Dubey ${ }^{2}$ \\ ${ }^{1 \& 2}$ Fluid and Turbomachinery Lab, Galgotias University, Greater Noida, India \\ *Corresponding author \\ E-Mail: wazeeradil@gmail.com
}

\begin{abstract}
Bernoulli's equation is found to be one of the most popular topics of the elementary physics. The paper presents the experimental behavior of the famous Bernoulli's equation when the piezometric heads are altered and varied with respect to the heads $10 \mathrm{~cm}$ and $15 \mathrm{~cm}$. The value of $h$ in centimeters have been recorded in altered time periods and heads and in all the nine tubes. The calculation of the total energy ( $E$ ) by changing the heads is obtained and the results achieved while equating the graphs between the total energy and distance from the reference point by changing the heads has been computed.
\end{abstract}

Keywords: Bernoulli's Equation, Piezometric, Total Energy Head, Discharge

\section{INTRODUCTION}

Bernoulli's theorem states that wheneverthere is a continuous connection between particles of flowing mass of liquid, the total energy at any section of flow will remain same provided there is no reduction or addition of energy at any point. The theorem is based on the law of conservation of energy. The equation states that at two sections of flow field the total energy remains the same, provided that there is no loss or gain of energy between the two sections. The equation is valid only for steady flow.

$$
E=\frac{p_{1}}{\rho g}+\frac{v_{1}^{2}}{2 g}+Z_{1}=\frac{p_{2}}{\rho g}+\frac{v_{2}^{2}}{2 g}+Z_{2}
$$

Where;

$\mathrm{E} \quad=$ Total energy

$\frac{p_{1}}{\rho g}=$ Pressure energy per unit weight of fluid or pressure

head at point 1 .

$\frac{v_{1}^{2}}{2 g}=$ Kinetic energy per unit weight or kinetic head at

point 1.

$Z_{1}=$ Potential energy per unit weight or potential head at point 1.

$\frac{p_{2}}{\rho g}=$ Pressure energy per unit weight of fluid or pressure head at point 2 . $\frac{v_{2}^{2}}{2 g}=$ Kinetic energy per unit weight or kinetic head at

point 2.

$Z_{2}=$ Potential energy per unit weight or potential head at point 2.

$p_{1}=$ pressure of fluid at point 1 .

$p_{2}=$ pressure of fluid at point 2 .

$v_{1}=$ velocity of fluid at point 1 .

$v_{2}=$ velocity of fluid at point 2 .

$\rho=$ density of fluid.

$g=$ acceleration due to gravity.

The terms in the Bernoulli equation as generally written in hydraulics are often referred to as heads since the units are commonly expressed as feet. This concept of fluid columns standing to various heights is valuable and appropriate in applications to the flow of incompressible fluids. However, when it is applied to compressible fluids considerable error may be introduced [1]. One possible interpretation of Bernoulli's equation is that there is a conversion of internal motion into directed motion [2]. The Bernoulli equation is well known in hydrodynamics [3-6] and electromechanics [7]. Recently its scope was also extended to Ferro hydrodynamics (FHD) [8, 9], which, according to Rosensweig [9], "deals with mechanics of fluid motion influenced by strong forces of magnetic polarization."

\section{DESCRIPTION OF SETUP}

The experimental Bernoulli's test rig is installed at Fluid and Turbo Machinery laboratory, School of Mechanical Engineering, Galgotias University, Greater Noida, India. The complete setup is well designed and arranged in a good quality environment. The present experimental setup for Bernoulli's theorem is self-contained recirculating unit. The setup accompanies the Sump tank, Constant Head tank, Centrifugal Pump for lifting water, Measuring tank, etc. Control and By-pass valves are also provided to regulate the flow of water in Constant Head tank. A conduit, made of Perspex, of varying cross-section is provided, which is having converging and diverging section. Piezometer tubes are fitted on this test section at regular interval. The inlet of 
the conduit is connected to constant head tank. At the outlet of conduit, a valve is provided to regulate the flow of water through the test section. After achieving the steady state, discharge through test section can be measured with the help of measuring tank and stop watch.

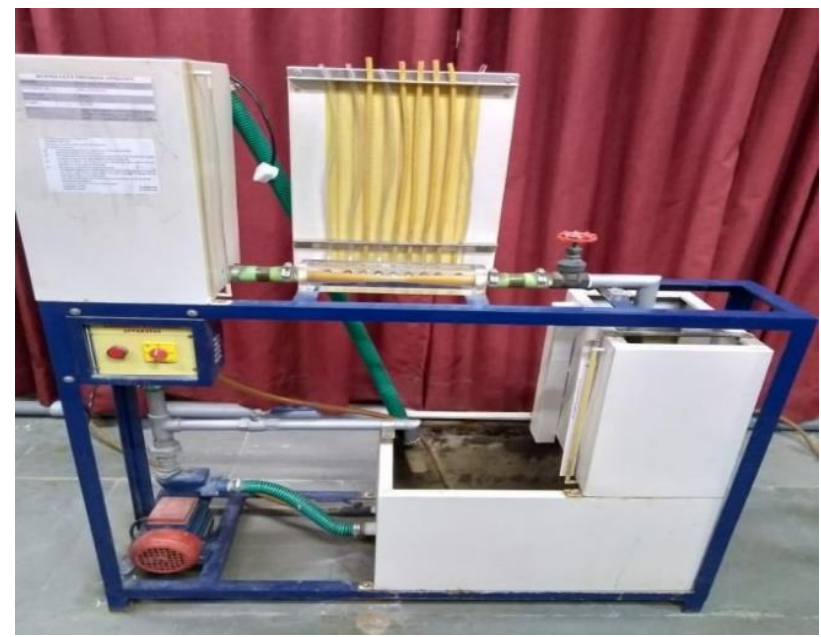

Fig. 1 Bernoulli’s experimental test rig.

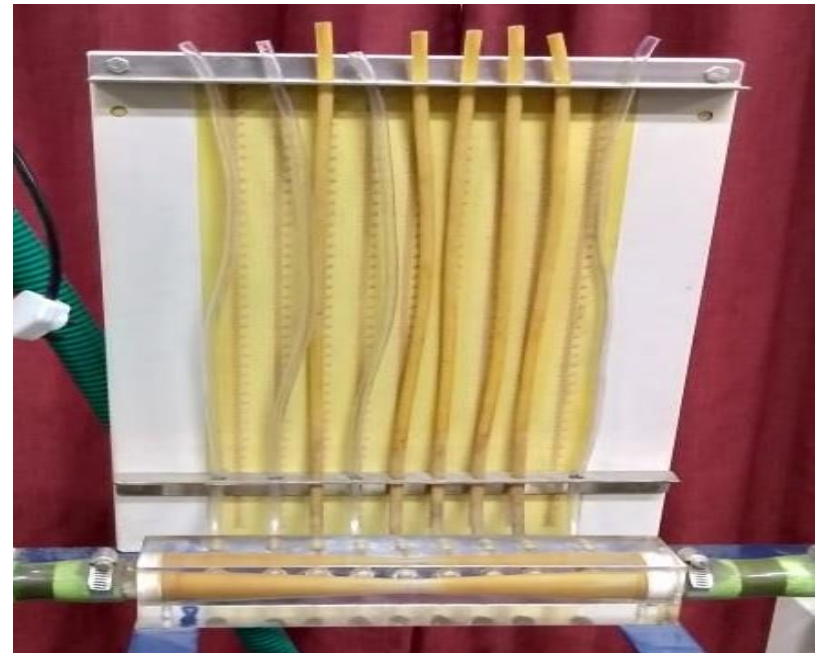

Fig. 2 Nine Piezometric tubes.

\section{A. Utilities required}

1. Bernoulli's experimental test rig

2. Power supply: Single phase, $220 \mathrm{~V}, 50 \mathrm{~Hz}, 5 \mathrm{Amp}$ with earth connection.

3. Water supply

4. Space required of floor area needed: $1.6 \mathrm{~m} * 0.5 \mathrm{~m}$.

5. Drain

\section{B. Specifications of the Setup}

Test Section

Piezometer tubes

Water circulation

Flow measurement piezometer, capacity 42 liters.

Sump tank
: Metallic Acrylic

: Material P.U. Tubes (9 Nos.)

: FHP pump

: Using measuring tank with

: Capacity 85 liters
Inlet tank

Stop watch

: Capacity 25 liters

: Digital

Control panel comprises : Standard ON/OFF switch, Mains Indicator, etc.

\section{EQUATIONS}

A. Discharge (Q):

$$
Q=\frac{A * R}{t}
$$

B. Velocity of fluid $(V)$ :

$$
V=\frac{Q}{a}
$$

C. Total Energy $(E)$ :

$$
\begin{gathered}
E=\frac{p}{\rho g}+\frac{v^{2}}{2 g}+Z \\
\frac{p}{\rho g}=h
\end{gathered}
$$

Where;

$\mathrm{E} \quad=$ Total Energy

$\frac{p}{\rho g}=$ Pressure energy per unit weight of fluid or

pressure head

$\frac{v^{2}}{2 g}=$ Kinetic energy per unit weight of kinetic head

$\mathrm{Z} \quad=$ Potential energy per unit weight or potential head

$\mathrm{P} \quad=$ Pressure of fluid ( $\mathrm{m}$ of water)

$\mathrm{V}=$ Velocity of fluid $(\mathrm{m} / \mathrm{s})$

$\mathrm{Q}=$ Discharge through test section

$\mathrm{v}=$ Volume of water collected in measuring tank

$\mathrm{t} \quad=$ Time taken for $\mathrm{R}$

$\mathrm{g}=$ Acceleration due to gravity $=9.8 \mathrm{~m} / \mathrm{s}^{2}$

A = Area of measuring tank $=0.1 \mathrm{~m}^{2}$

TABle I TABle Showing Cross Sectional AREA AND DistANCE From REFERENCE POINT OF TEST POINTS

\begin{tabular}{|c|c|c|}
\hline $\begin{array}{c}\text { S. No. of } \\
\text { Test Points }\end{array}$ & $\begin{array}{c}\text { Cross sectional area, } \\
\mathbf{a}\left(\mathbf{m}^{2}\right)\end{array}$ & $\begin{array}{c}\text { Distance from Reference } \\
\text { point, } \mathbf{S}(\mathbf{m})\end{array}$ \\
\hline 1 & $6.1575 \times 10^{-4}$ & 0.03 \\
\hline 2 & $4.9088 \times 10^{-4}$ & 0.059 \\
\hline 3 & $3.4636 \times 10^{-4}$ & 0.088 \\
\hline 4 & $2.4053 \times 10^{-4}$ & 0.117 \\
\hline 5 & $1.5394 \times 10^{-4}$ & 0.146 \\
\hline 6 & $2.4053 \times 10^{-4}$ & 0.175 \\
\hline 7 & $3.4636 \times 10^{-4}$ & 0.204 \\
\hline 8 & $4.9088 \times 10^{-4}$ & 0.233 \\
\hline 9 & $6.1575 \times 10^{-4}$ & 0.262 \\
\hline
\end{tabular}




\section{RESULTS AND DISCUSSION}

The value of $h(\mathrm{~cm})$ when computed from $\mathrm{R}=10 \mathrm{~cm}$ indicates a scale of $23.5 \mathrm{~cm}$ in the first tube and gradually inclines to decrease from second tube onwards from $22.8 \mathrm{~cm}$ to $15.5 \mathrm{~cm}$ in fifth tube. Straight from sixth tube the measure of $h$ again increases and continues till ninth tube to the scale of $20.2 \mathrm{~cm}$ thus taking an overall time of 55.8 seconds. Similarly when $h$ is computed by taking $\mathrm{R}=15 \mathrm{~cm}$, parallel trend prevails and takes 89 seconds for its completion.

Total Energy (E) is calculated for each tube and in order to recognize the trend, the value of total energy in the first tube is $0.328 \mathrm{~m}$ which descends to $0.32 \mathrm{~m}$ in second tube and then again upsurges in third tube by $0.329 \mathrm{~m}$. From fourth tube onwards the value of E decreases till the last tube.

Table II Values Of H At Different Piezometric Head (R)

\begin{tabular}{|c|c|c|c|c|c|c|c|c|c|c|c|}
\hline \multirow{2}{*}{ S. No. } & \multirow{2}{*}{$\mathbf{R}(\mathbf{c m})$} & \multirow{2}{*}{$\mathbf{t}(\mathbf{s e c})$} & \multicolumn{8}{|c|}{$\mathbf{h}(\mathbf{c m})$ at piezometric tube no. } \\
\cline { 4 - 12 } & & & $\mathbf{1}$ & $\mathbf{2}$ & $\mathbf{3}$ & $\mathbf{4}$ & $\mathbf{5}$ & $\mathbf{6}$ & $\mathbf{7}$ & $\mathbf{8}$ & $\mathbf{9}$ \\
\hline 1 & 10 & 55.8 & 23.5 & 22.8 & 21.5 & 19.5 & 15.5 & 18.9 & 19.5 & 20 & 20.2 \\
\hline 2 & 15 & 89 & 32.5 & 32 & 31.8 & 30.3 & 27 & 28.8 & 31.5 & 32 & 32.5 \\
\hline
\end{tabular}

As evident from the graph between the Total Energy (E) and Distance $(\mathrm{S})$, when $\mathrm{R}=10 \mathrm{~cm}$, the graph primarily follows a linear contour and suddenly increases when the energy is beyond $0.5 \mathrm{~m}$ and then slowly decreases. When $\mathrm{R}=15 \mathrm{~cm}$, the overall graph represents a decrease in the total energy with the increase in the distance. There is a slight increase of $\mathrm{E}$ when the distance is between $0.05-0.1 \mathrm{~m}$.

TABLE III TOTAL ENERGY OUTCOME WITH RESPECTIVE TO PIEZOMETRIC TUBE NUMBERS

\begin{tabular}{|c|c|c|c|}
\hline S. No. & Tube No. & $\begin{array}{c}\text { Total Energy, E, } \\
\text { when R=10cm }\end{array}$ & $\begin{array}{c}\text { Total Energy, E, } \\
\text { when R=15cm }\end{array}$ \\
\hline 1 & 1 & 0.3558 & 0.328 \\
\hline 2 & 2 & 0.3492 & 0.32 \\
\hline 3 & 3 & 0.34 & 0.329 \\
\hline 4 & 4 & 0.33 & 0.327 \\
\hline 5 & 5 & 0.55 & 0.321 \\
\hline 6 & 6 & 0.48 & 0.312 \\
\hline 7 & 7 & 0.4 & 0.31 \\
\hline 8 & 8 & 0.39 & 0.309 \\
\hline 9 & 9 & 0.35 & 0.3 \\
\hline
\end{tabular}

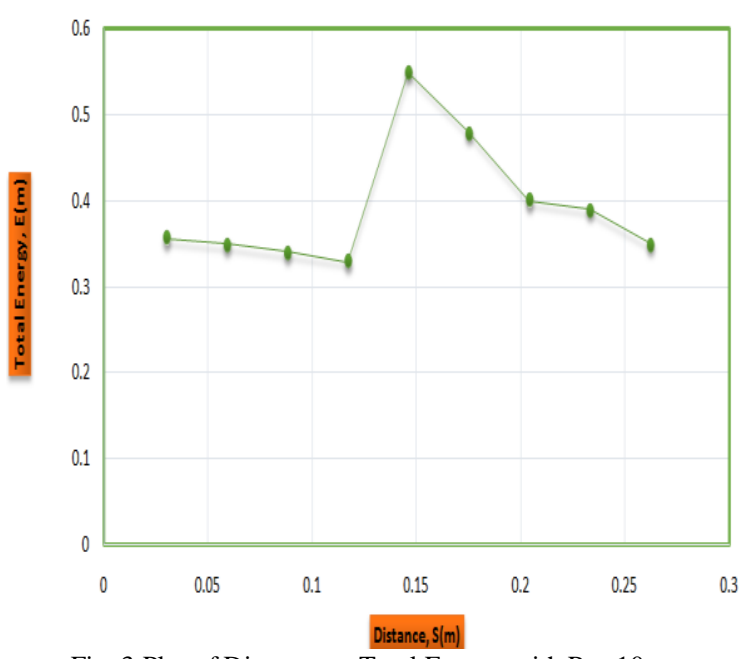

Fig. 3 Plot of Distance vs Total Energy with $\mathrm{R}=10 \mathrm{~cm}$

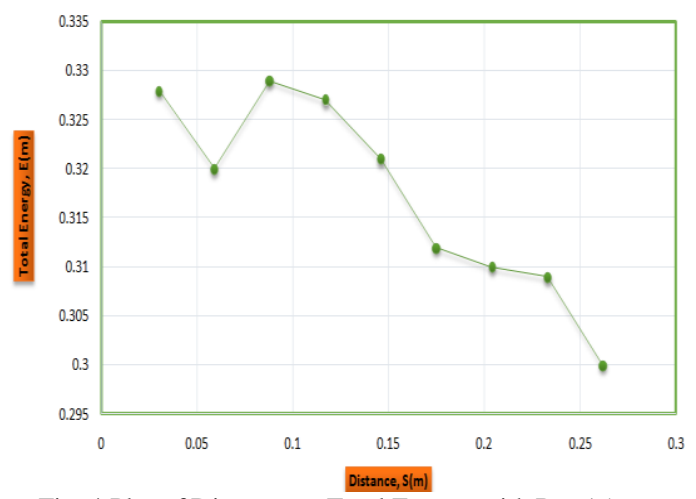

Fig. 4 Plot of Distance vs Total Energy with $\mathrm{R}=15 \mathrm{~cm}$

\section{CONCLUSION}

1. When $h$ is computed with $\mathrm{R}=10 \mathrm{~cm}$ then its value first increases up to $5^{\text {th }}$ tube and then increases from $6^{\text {th }}$ tube onwards. Similar trend is observed when $\mathrm{R}=15 \mathrm{~cm}$ is taken for $h$ calculation.

2. When $\mathrm{R}=10 \mathrm{~cm}$, the graph between $\mathrm{E}$ and $\mathrm{S}$ originates with a linear relationship and ends with a decrease of $\mathrm{E}$ while increasing $\mathrm{S}$.

3. When $R=15 \mathrm{~cm}$, the graph between $\mathrm{E}$ and $\mathrm{S}$ signifies an overall decrease in total energy when $\mathrm{S}$ is increased.

\section{REFERENCES}

[1] B. F. Ruth, D. R. Boylan, “Application of Bernoulli's Equation to Buoyant Systems”, A.I.Ch. E Journal., Vol. 2, No. 2, pp. 277-279.

[2] Robert P. Bauman, Rolf Schwaneberg, "Interpretation of Bernoulli's equation", Phys. Teach., Vol. 32, No. 478, 1994, DOI: 10.1119/1.2344087.

[3] L. M. Milne Thompson, Theoretical Hydrodynamics., 5th ed Macmillan \& Co. London, 1974.

[4] H. Lamb, Hydrodynamics, Dover, New York, 1945.

[5] R. B. Bird, W. E.Stewart, and E. N. Lightfoot, Transport Phenomena., Wiley, New York, 1960.

[6] G. K. Batchelor, An Introduction of Fluid Dynamics, Cambridge Univ. Press, London/New York, 1967.

[7] J. R. Melcher, Continuum Electromechanics, MIT Press, Cambridge, MA, 1981.

[8] R. E. Rosensweig, Advances in Electronics and Electron Phys., Vol. 48, pp. 103-199, 1979.

[9] R. E. Rosensweig, Ferrohydrodynamics, Cambridge Univ. Press, Cambridge, 1985. 